\title{
International Consensus on Diverticulosis and Diverticular Disease. Statements from the 3rd International Symposium on Diverticular Disease
}

\author{
Antonio Tursi ${ }^{1}$, Giovanni Brandimarte ${ }^{2}$, Francesco Di Mario ${ }^{3}$, Angel Lanas ${ }^{4}$, Carmelo Scarpignato ${ }^{5}$, Mauro Bafutto ${ }^{6}$, Giovanni \\ Barbara $^{7}$, Gabrio Bassotti ${ }^{8}$, Gian Andrea Binda ${ }^{9}$, Alberto Biondi ${ }^{10}$, Sebastiano Biondo ${ }^{11}$, Ginevra Cambie ${ }^{3}$, Claudio Cassieri ${ }^{2}$, Antonio \\ Crucitti $^{12}$, Dan L. Dumitrascu ${ }^{13}$, Walter Elisei ${ }^{14}$, Ricardo Escalante ${ }^{15}$, László Herszenyi ${ }^{6}$, Wolfgang Kruis ${ }^{17}$, Juozas Kupcinskas ${ }^{18}$, Adi \\ Lahat $^{19}$, Piera G. Lecca ${ }^{2}$, Giovanni Maconi ${ }^{20}$, Peter Malfertheiner ${ }^{21}$, Andrea Mazzari ${ }^{12}$, Fermìn Mearin ${ }^{22}$, Tomica Milosavljevic ${ }^{23}$, \\ Gerardo Nardone $^{24}$, Enio Chavez de Oliveira ${ }^{25}$, Alfredo Papa $^{26}$, Savvas Papagrigoriadis ${ }^{27}$, Miguel Pera ${ }^{28}$, Roberto Persiani ${ }^{10}$, \\ Marcello Picchio $^{29}$, Jaroslaw Regula ${ }^{30}$, Davor Štimac ${ }^{31}$, Neil Stollman $^{32}$, Lisa L. Strate ${ }^{33}$, Alessandra Violi ${ }^{3}$, Marjorie M.D. Walker ${ }^{34}$
}

1) Gastroenterology Service, ASL BAT, Andria (BT), Italy; 2) Division of Internal Medicine and Gastroenterology, "Cristo Re" Hospital, Rome, Italy; 3) Department of Medicine and Surgery, Gastroenterology Unit, University of Parma, Parma, Italy; 4) Service of Digestive Diseases, University Clinic Hospital Lozano Blesa, University of Zaragoza, IIS Aragón, Zaragoza, Spain; 5) Faculty of Medical Sciences, United Campus of Malta, San Giljan, Malta; 6) Instituto Goiano de Gastroenterologia e Endoscopia Digestiva Ltda, Rua 246, 25 Setor Coimbra, Goiânia, Goiás, Brazil; 7) Department of Clinical Medicine, Section of Gastroenterology, "S. Orsola" Hospital, University of Bologna, Bologna, Italy; 8) Department of Clinical and Experimental Medicine, Gastroenterology and Hepatology Section, "Santa Maria della Misericordia" Hospital, University of Perugia, San Sisto (PG), Italy; 9) Department of Surgery, “Galliera” Hospital, Genoa, Italy; 10) Department of Surgical Sciences, First General Surgery Unit, Catholic University, „A. Gemelli” University Hospital, Rome, Italy; 11) Department of General and Digestive Surgery, Colorectal Unit, Bellvitge University Hospital and IDIBELL, University of Barcelona, Barcelona, Spain; 12) Division of General Surgery, „Cristo Re” Hospital, Rome, Italy; 13) 2nd Medical Department, Iuliu Hatieganu University of Medicine and Pharmacy Cluj-Napoca, Romania ; 14) Division of Gastroenterology, ASL Roma 6, Albano Laziale (Roma), Italy; 15) Universidad Central de Venezuela, Loira Medical Center, Caracas, Venezuela; 16) 2nd Department of Medicine, Semmelweis University, H-1088 Budapest, Hungary; 17) Innere Medizin, Evangelische Krankenhaus Kalk, Cologne, Germany; 18) Institute for Digestive Research, Lithuanian University of Health Sciences, Kaunas; Department of Gastroenterology, Lithuanian University of Health Sciences, Kaunas, Lithuania; 19) Department of Gastroenterology, Chaim Sheba Medical Center, Tel Hashomer, Ramat Gan 52651, Israel; 20) Gastrointestinal Unit, Department of Clinical Sciences, "L.Sacco" University Hospital, Milan, Italy; 21) Department of Gastroenterology, Hepatology and Infectious Diseases, Otto-vonGuericke University Hospital, Magdeburg, Germany; 22) Servicio Aparato Digestivo, Centro Médico Teknon, Barcelona, Spain; 23) Clinical Centre of Serbia, University of Belgrade, Serbia; 24) Department of Clinical and Experimental Medicine, University „Federico II”, Naples, Italy ; 25) Hospital Ortopèdico de Goiania (St Aeroporto), Goiânia, Goiás, Brazil; 26) Division of Internal Medicine and Gastroenterology, CIC "Columbus", Catholic University, "A. Gemelli” University Hospital, Rome, Italy; 27) Department of Colorectal Surgery, King's College Hospital, London, United Kingdom; 28) Sección de Cirugía Gastrointestinal, Hospital Universitari del Mar, Barcelona, Spain; 29) Division of General Surgery, “P. Colombo” Hospital, ASL Roma 6, Velletri (Roma), Italy; 30) Department of Gastroenterology, Hepatology and Clinical Oncology, Medical Postgraduate Education Centre; Department of Gastrointestinal Oncology, Maria Sklodowska-Curie Clinical Oncology Institute, Warsaw, Poland; 31) Division of Internal Medicine, University Hospital, Rijeka, Croatia; 32) Division of Gastroenterology, Department of Medicine, University of California San Francisco, Oakland, CA, USA; 33) Division of Gastroenterology, Department of Medicine, Harborview Medical Center, University of Washington Medical School, Seattle, Washington, USA; 34) University of Newcastle, Faculty of Health and Medicine, School of Medicine \& Public Health, Australian Gastrointestinal Research Alliance, Callaghan NSW 2308, Australia

Address for correspondence: Antonio Tursi, MD Via Torino, 49 76123 Andria (BT) - Italy antotursi@tiscali.it

\begin{abstract}
The statements produced by the Chairmen and Speakers of the 3rd International Symposium on Diverticular Disease, held in Madrid on April 11th-13th 2019, are reported. Topics such as current and evolving concepts on the pathogenesis, the course of the disease, the news in diagnosing, hot topics in medical and surgical treatments, and finally, critical issues on the disease were reviewed by the Chairmen who proposed 39 statements graded according to level of evidence and strength of recommendation. Each topic was explored focusing on the more relevant clinical questions. The vote was conducted on a 6-point scale and consensus was defined a priori as $67 \%$ agreement of the participants. The voting group consisted of 124 physicians from 18 countries, and agreement with all statements was provided. Comments were added explaining some controversial areas.
\end{abstract}


Key words: diverticulosis - diverticular disease - diverticulitis - consensus - diagnosis - medical therapy - surgical therapy.

\begin{abstract}
Abbreviations: AD: acute diverticulitis; 5-ASA: 5-aminosalycilic-acid; CRP: C-reactive protein; CE-CT: contrast-enhanced computer tomography; CRC: colorectal cancer; CT: computer tomography; DD: diverticular disease; DICA: Diverticula Inflammation and Complications Assessment; EL: evidence level; FC: fecal calprotectin; IBS: irritable bowel syndrome; IUS: intestinal ultrasound; RG: recommendation grade; SCAD: segmental colitis associated with diverticulosis; SUDD: symptomatic uncomplicated diverticular disease ; TNFa: tumour necrosis factor alpha.
\end{abstract}

\section{INTRODUCTION}

Diverticulosis of the colon is the most frequent anatomical alteration of the colon in the developed countries, and the highest rates occur in the United States and Europe. This condition nowadays ranks as fifth most important gastrointestinal disease in terms of direct and indirect costs $[1,2]$. When diverticulosis becomes symptomatic, it is called "diverticular disease" (DD), a term generally including symptomatic uncomplicated diverticular disease (SUDD) and acute diverticulitis (AD) $[1,2]$

Although the pathogenesis and management of diverticulosis and DD remain uncertain, new hypotheses and observations are changing the pharmacological and surgical management of DD.

Recommendations for the diagnosis and treatment of DD have been issued by many medical societies in various countries. However, these recommendations are often conflicting [3, 4$]$, generating uncertainties in the clinician and dissatisfaction in patients.

We have summarised the current perspective on DD in this consensus conference report, aiming to develop guidelines for the clinical, diagnostic and therapeutic management of DD in light of the presentations during the 3rd International Symposium on Diverticular Disease, held in Madrid on April $11^{\text {th }}-13^{\text {th }}, 2019$.

\section{METHODS}

The primary aim of this document was to provide clinical guidelines for appropriate definition, diagnosis and management of diverticulosis and DD according to the opinion of the participants to the 3rd International Symposium on Diverticular Disease, held in Madrid on April 11-13, 2019. The promoters of this initiative were the Chairmen of this International Symposium (A.T., F.D.M., G.B., A.L., C.S.). This International Symposium on Diverticular Disease was constituted by six main sessions (current and evolving concepts on the pathogenesis, news on the course of the disease, the news in diagnosing, hot topics in medical therapy, hot topics in surgical treatments, and finally critical issues on the disease). The evidence-based Delphi-like process developed consensus statements following proposals by designated speakers. The process allowed individual feedback and changes of views during the process regulated by the coordinators of each session and the Chairmen of the Symposium.

The principal steps in the process were: (a) selection of the consensus group; (b) identification of areas of clinical importance; (c) systematic literature reviews by using Medline/ PubMed and the Cochrane Database to identify evidence to support each statement, draft statements and discussion with the coordinators of each session and the Chairmen of the Symposium supported by the evidence specific to each statement. The modified statements of the 2 nd International Symposium [5] were used to define statements of this Symposium. Evidence-based discussions with key references were provided for each statement, and a two-rounds assessing statements was conducted.

Each recommendation was graded according to the Oxford Centre for Evidence-Based Medicine, according to the level of evidence (EL) and grade of recommendation (RG) [6]. Participants, constituted by multi-disciplinary professionals/ experts such as gastroenterologists, gastrointestinal endoscopists, surgeons, pathologists, internists, infectious diseases and general practitioners, were asked to vote each statement linked to the session at the ending of the same session. Chairmen, speakers, and members of the scientific board did not take part to vote statements. The agreement/ disagreement level was scored on a six-point Likert scale as follows: A+: strongly agree; A:

agree with minor reservations; A-: agree with major reservations; D-: disagree with major reservations;

$\mathrm{D}$ : disagree with minor reservations; $\mathrm{D}+$ : strongly disagree. Level of agreement was expressed as percentage of each point of the scale. Consensus was defined a priori as agreement by at least $67 \%$ of respondents.

The format of the following recommendations comprises the question, the statement, its level of evidence and strength of recommendation, and the percentage agreement of the global consensus group on the final version.

In the present document the statements are accompanied by comments made by Chairmen of the Meeting. In some areas the evidence level is low, reflecting the lack of randomised trials and/or good quality studies. For some topics only the expert opinion was considered, where appropriate.

Analysis was performed only assessing participant voting all statements.

\section{STATEMENTS}

One hundred and twenty-four participants voted all statements. They came from 18 countries: 1 from Australia, 5 from Bulgaria, 1 from Croatia, 1 from Germany, 1 from Israel, 60 from Italy, 3 from Mexico, 1 from The Netherlands, 2 from Poland, 2 from Portugal, 2 from Romania, 3 from Russia, 1 from Serbia, 2 from Slovakia, 1 from Slovenia, 3 from Spain, 3 from Tunisia, 1 
from Hungary, and 2 from United States of America. One hundred and two were gastroenterologists, 15 surgeons, 3 internists, 3 general pratictioners, and 1 specialist on infectious diseases.

\section{Pathogenesis}

1.1 There is no sufficient evidence that fiber intake prevents the development of diverticulosis. [EL: $2 b ; G R: B$ ]

Consensus levels of agreement: A+38.71\%; A 41.94\%; A$11.29 \%$; D- 3.23\%; D 2.42\%; D+ 2.42\%.

1.2 Diverticular disease and diverticulitis are more likely to develop in individuals with genetic predisposition. [EL: $1 b ; G R: A]$

Consensus levels of agreement: A+ 41.13\%; A 37.10\%; A16.94\%; D- 1.61\%; D 3.23\%; D+ 0\%.

1.3 The routine clinical use of genetic markers is not recommended for the prevention, diagnosis and management of diverticular diseases. [EL: 1b; GR: A]

Consensus levels of agreement: A+70.16\%; A 13.71\%; A$14.52 \%$; D- 0\%; D: $0.81 \%$; D+ 0.81\%.

1.4 Neuromuscular dysfunction represents a relevant pathogenetic factor in colonic diverticulosis. [EL: 3a; GR: C]

Consensus levels of agreement: A+ 49.19\%; A 38.71\%; A$10.48 \%$; D- $1.61 \%$; D: 0\%; D+ 0\%.

1.5 Colonic motor and sensory abnormalities may play a role in the genesis of abdominal pain in patients with colonoscopy symptomatic uncomplicated diverticular disease (SUDD). [EL: 4a; GR: C]

Consensus levels of agreement: A+ 39.52\%; A 46.77\%; A$11.29 \%$; D- $1.61 \%$; D: 0\%; D+ 0.81\%.

1.6 In community subjects and patients attending colonoscopy with no prior history of diverticulitis and with asymptomatic diverticulosis and no endoscopic inflammation it is highly unlikely there will be inflammatory changes in biopsy of the intervening colonic mucosa. [EL: 1b; GR: A]

Consensus levels of agreement: A+ 56.45\%; A $21.77 \%$; A12.90\%; D- 4.03\%; D: 4.03\%; D+ 0.81\%.

1.7 Patients with symptomatic uncomplicated diverticular disease (SUDD) may have low-grade inflammatory changes at the molecular level and microbiome in the biopsy without endoscopic inflammation. [EL 3a; GR: B]

Consensus levels of agreement: A+39.52\%; A 45.16\%; A$14.52 \%$; D- 0.81\%; D: 0\%; D+ 0\%.

1.8 A diet high in dietary fiber is associated with a decreased risk of diverticulitis. [EL: 2b; GR: D]

Consensus levels of agreement: A+52.42\%; A 40.32\%; A$2.42 \%$; D- 3.23\%; D: 0\%; D+ 1.61\%.

1.9 Obesity is associated with an increased risk of diverticulitis and diverticular bleeding. [EL: 2a; GR: D]

Consensus levels of agreement: A+67.74\%; A 24.19\%; A$3.23 \%$; D- 2.42\%; D: $1.61 \%$; D+ 0.81\%.

\section{Comments}

These statements point out the new evidences on the pathogenesis of diverticulosis and diverticular disease. The first three statement point out the role of genetic factors to the development of DD and AD [7-14]. The fourth and fifth statements point out the significant role of neuromuscular abnormalities in the pathogenesis of diverticulosis and DD [15-20]. The sixth and the seventh statement point out that diverticulosis is a merely expression of an anatomical alteration [21-23], while symptomatic uncomplicated diverticular disease (SUDD) may have overt inflammation microscopic inflammation even without any endoscopic inflammation [24, 25 ]. The last two statements point out the role of high fiber diet in reducing the risk of acute diverticulitis [26-30], and more recent evidences are available about the role of obesity on occurrence of DD complications [31, 32]. Overall consensus about these statement was very high, since all of them reached $>80 \%$ agreement among respondents.

\section{Course of the disease}

2.1 Symptomatic Uncomplicated Diverticular Disease (SUDD) is a distinct clinical syndrome characterized by recurrent abdominal symptoms attributed to diverticula in the absence of clinical, laboratory, or radiographic markers of overt inflammation. [EL: 1c; RG: B]

Consensus levels of agreement: A+ 49.19\%; A 37.10\%; A$11.29 \%$; D- 0\%; D: $1.61 \%$; D+ 0.81\%.

2.2 The pathophysiology is SUDD is poorly understood, with some evidence suggesting altered colonic motility, visceral hypersensitivity, microbiome alterations and/or subclinical inflammation playing etiological roles. [EL: 4; RG: D]

Consensus levels of agreement: A+ 55.65\%; A 30.65\%; A12.10\%; D- 0.81\%; D: 0.81\%; D+ 0\%.

2.3 There is no evidence to suggest that bowel habits or a change in those habits determine the evolution to diverticulitis. [EL: 1c; RG: B]

Consensus levels of agreement: A+ 48.49\%; A 33.06\%; A$12.90 \%$; D- $4.03 \%$; D: 0\%; D+ 0.81\%.

2.4 SUDD post-acute diverticulitis is a chronic inflammatory disease with prolonged chronic symptoms, high levels of systemic serum inflammatory markers, high levels of tissue inflammatory cytokine and chronic inflammatory infiltrates in the affected colonic tissue. [E: 2C; RG: B]

Consensus levels of agreement: A+ 49.19\%; A 18.55\%; A20.16\%; D- 8.87\%; D: $1.81 \%$; D+ 1.81\%.

2.5 There is still no definite evidence that rifaximin reduces acute episodes of diverticulitis. [EL: 4; RG: D]

Consensus levels of agreement: A+ 45.57\%; A 39.52\%; A8.06\%; D- 4.84\%; D: 1.61\%; D+ 0\%.

2.6 There are some evidences that mesalazine could reduce symptoms following acute episode of diverticulitis. [EL: $3 a ; R G: B$ ]

Consensus levels of agreement: A+17.74\%; A 49.19\%; A28.23\%; D- 1.61\%; D: 1.61\%; D+ 1.61\%. 
2.7 At present, there is no evidence that mesalazine reduces acute episodes of diverticulitis. [EL: 1c; RG: B]

Consensus levels of agreement: A+ 52.42\%; A 28.23\%; A$11.29 \%$; D- 5.65\%; D: $1.61 \%$; D+ 0.81\%.

\section{Comments}

These statements point out the new evidences about the evolution of diverticulosis towards occurrence of SUDD and acute diverticulitis. The first two statements define clearly that SUDD is a distinct clinical syndrome, with distinct clinical characteristics from irritable bowel syndrome (IBS) [33, 34], and have specific characteristics about cytokine expression and microbiota signature $[24,35-39]$. The third statement clarify that, based on current evidences, changing of bowel habits do not seems to influence the evolution towards $\mathrm{AD}$ [40]. The forth statement points out patients experiencing SUDD following an episode of acute diverticulitis have persistence of inflammation in terms of histological inflammation and increased expression of cytokines, findings that underscore the risk of $\mathrm{AD}$ recurrence $[41,42]$. The last three statements point out that, at present, there are no clear evidences on how to prevent $\mathrm{AD}$ occurrence and its recurrence. Neither rifaximin nor mesalazine seems to be effective on both these topics [5, 43-44], while mesalazine seems to reduce symptoms following an episode of $\mathrm{AD}[45$, 46]. This because the trial design was not optimal, and this was particularly true for trials investigating mesalazine. Also the overall consensus about these statement was very high, since all of them reached $>80 \%$ agreement among respondents.

\section{Diagnosis}

3.1 No single biomarker is sensitive and specific enough to be recommended as diagnostic tool for symptomatic uncomplicated diverticular disease. [EL: 1a; GR: A]

Consensus levels of agreement: A+83.87\%; A 15.32\%; A0\%; D- 0\%; D: 0.81\%; D+ 0\%.

3.2 C-reactive protein levels $>150 \mathrm{mg} / \mathrm{l}$ strongly predicts complicated diverticulitis. [EL: 1a; GR: A]

Consensus levels of agreement: A+ 43.55\%; A 50\%; A6.45\%; D- 0\%; D: 0\%; D+ 0\%.

3.3 Faecal Calprotectin might be useful in distinguishing symptomatic uncomplicated diverticular disease from irritable bowel syndrome, but a cut-off level needs to be identified. [EL: 3c; GR: C]

Consensus levels of agreement: A+ 38.71\%; A 45.97\%; A8.87\%; D- 0.81\%; D: $2.42 \%$; D+ 3.23\%.

3.4 Contrast-enhanced computer tomography (CE-CT) should be considered as the first-line colonic examination since it offers a more comprehensive evaluation of uncomplicated and complicated forms; CE-CT can also be used to guide therapeutic interventions. [EL 1b;GR: A]

Consensus levels of agreement: A+38.71\%; A 45.97\%; A8.87\%; D- 0,81\%; D: 2.42\%; D+ 3.23\%.

3.5 Ultrasound has slightly lower sensitivity and specificity compared to CT in the assessment of acute diverticulitis and its use as the first-line diagnostic procedure - followed by CT scan in the case of inconclusive sonographic findings - may spare the use of CT in more than 50\% of cases. [EL: 1a; GR: A]

Consensus levels of agreement: A+ 55.65\%; A 23.39\%; A$18.55 \%$; D- $1.61 \%$; D: $0.81 \%$; D+ 0\%.

3.6 Ultrasound coupled with i.v. contrast agents (CEUS) differentiates between peri-intestinal phlegmon and abscess and demonstrates the real extension of the abscess in acute diverticulitis.

Ultrasound-guided drainage, when feasible, is the preferable option for abscesses larger than $3 \mathrm{~cm}$. [EL: 4; GR: C]

Consensus levels of agreement: A+ 50\%; A 41.13\%; A- 0\%; D- $0.81 \%$; D: 0\%; D+ 0\%.

3.7 Ultrasound is useful to monitor the patients after the acute diverticulitis and in particular the lesions treated conservatively. [EL: $2 b ; G R: B$ ]

Consensus levels of agreement: A+33.87\%; A 48.39\%; A15.39\%; D- 2.42\%; D: 0\%; D+ 0\%.

3.8 Ultrasound may be of help in detecting symptomatic uncomplicated diverticular disease (SUDD) of the colon. [EL: 4; GR: C]

Consensus levels of agreement: A+ 27.42\%; A 52.42\%; A$13.71 \%$; D- 3.23\%; D: $1.61 \%$; D+ 1.61\%.

3.9 A prompt colonoscopy (i.e. within 12-24 h) is mandatory for diagnosis and to direct therapy in diverticular bleeding. Massive bleeding should be managed with selective angiography. [EL: 2a; GR: B]

Consensus levels of agreement: A+ 45.97\%; A 41.94\%; A6.45\%; D- 5.65\%; D: 0\%; D+ 0\%.

3.10. DICA endoscopic classification seems to have a predictive value on the outcome of the disease. EL: 1b; GR: B

Consensus levels of agreement: A+ 47.58\%; A 45.97\%; A4.03\%; D- 2.42\%; D: 0\%; D+ 0\%.

\section{Comments}

These statements point out the new evidences about the role of diagnosis in diagnosing and managing SUDD and AD. The first three statements confirm the important predicting value of C-reactive protein (CRP) in define the presence and the severity of acute diverticulitis $[47,48]$, and that fecal calprotectin (FC) may be useful in differentiating between SUDD and IBS [35]. The forth statement confirms that the contrast-enhanced computer tomography is the gold standard to pose the diagnosis of $\mathrm{AD}$ and its complications [49]. The statements 3.5-3.8 underscore the increasing role of the intestinal ultrasound (IUS) in diagnosis both SUDD and AD, underscoring also the limit of this technique, namely that it operator-sensitive [50-52]. The statement 3.9 points out the role of colonoscopy in those people. In particular, it underscore the role of colonoscopy in managing diverticular bleeding, which is the main cause of lower gastrointestinal bleeding and linked to the advanced age and the numerous, associated comorbidities [53-55]. The last statement point out the attention on the first validated endoscopic classification on diverticulosis and 
diverticular disease, called DICA (Diverticular Inflammation and Complication Assessment) [55]. This classification, very easy to use, has a significant predicting value on the outcome of the disease (57), and has also a significant interobserver agreement in real life [58]. The overall consensus about these statement was very high, since all of them reached $>80 \%$ agreement among respondents.

\section{Medical treatment}

4.1 Rifaximin plus fibre is effective in reducing symptoms in SUDD patients compared to fibre alone. [EL: $2 b ; G R: B$ ]

Consensus levels of agreement: A+ 66.94\%; A 28.23\%; A$3.23 \%$; D- $1.61 \%$; D: 0\%; D+ 0\%.

4.2 Mesalazine is effective in reducing symptoms in SUDD patients. [EL: 1b; GR: A]

Consensus levels of agreement: A+51.61\%; A 34.68\%; A$11.29 \%$; D- $1.61 \%$; D: 0.81\%; D+ 0\%.

4.3 There are some evidences that probiotics could be effective in reducing symptoms in SUDD patients [EL: 3a; GR: B]

Consensus levels of agreement: A+32.26\%; A 36.29\%; A28.23\%; D- 3.23\%; D: 0\%; D+ 0.81\%.

\section{Comments}

These statements focused their attention just on the treatment of SUDD, which is still under active debate. In particular, focusing their attention on the efficacy of non-absorbable antibiotics (namely rifaximin), anti-inflammatory drugs (namely mesalazine), and probiotics. The first statement confirms that rifaximin, especially when associated with fibre, is effecting in reducing symptoms in SUDD $[43,59]$. The second statement claims that mesalazine is also effective in reducing symptoms in those people and in preventing its recurrence during the followup $[46,60,61]$. The last statement claims that there are some interesting news in using probiotics in those people [61,62], but data are still too heterogeneous to drawn any definite conclusions. It is noteworthy the impressive overall consensus about these statement, reaching $>90 \%$ agreement among respondents.

\section{Surgical treatment}

5.1 Treatment of acute uncomplicated diverticulitis (AUD) without antibiotics is safe and effective and it is not associated with worse outcomes, including need for surgery, complications, recurrence and lenght of hospital stay. [EL: 2b; GR: B]

Consensus levels of agreement: A+28.23\%; A 41.94\%; A$13.71 \%$; D- $8.87 \%$; D: $3.23 \%$; D+ $4.03 \%$.

5.2 In Uncomplicated Acute Diverticulitis antibiotic therapy is still considered in patients immunocompromised, with severe comorbidities $(A S A>2)$ and with sign of sepsis. [EL: 3b; GR:C]

Consensus levels of agreement: A+79.03\%; A 20.97\%; A$0 \%$; D- 0\%; D: 0\%; D+ 0\%.

5.3 There are some evidence that high CPR level (>170 $\mathrm{mg} / \mathrm{ml}$ ) or a initial CT findings of fluid collection and longer inflamed colon could be useful factors in selecting patients who could benefit of antibiotic treatment, but these preliminary data need to be confirmed by further studies. [EL: 4; GR: C]

Consensus levels of agreement: A+69.35\%; A 28.23\%; A$2.42 \%$; D- 0\%; D: 0\%; D+ 0\%.

5.4 The open approach to acute diverticulitis in urgent/ emergent setting should be preferred for patients with hemodynamic instability, or when an adequate expertise in colorectal laparoscopy is not available. [EL: 4; GR: B]

Consensus levels of agreement: A+82.26\%; A 14.52\%; A$3.23 \%$; D- 0\%; D: 0\%; D+ 0\%.

5.5 Laparoscopic resection is safe and provides faster recovery in uncomplicated cases: cases; it has to be performed by well-trained surgeons. [EL: 2b; GR: B]

Consensus levels of agreement: A+77.42\%; A 20.97\%; A$1.61 \%$; D- 0\%; D: 0\%; D+ 0\%.

5.6 Laparoscopic peritoneal lavage may be an alternative to manage purulent peritonitis Hinchey III in diverticular disease. [EL: 4; GR: B]

Consensus levels of agreement: A+19.35\%; A 50\%; A16.94\%; D- 8.87\%; D: 4.84\%; D+ 0\%.

5.7 The decision to perform elective resection after one or more episodes of $A D$ should be undertaken on a "case-by-case" basis. [EL: 2b; GR: B]

Consensus levels of agreement: A+71.77\%; A 25\%; A$3.23 \%$; D- 0\%; D: 0\%; D+ 0\%.

\section{Comments}

These statements focused their attention mainly on the surgical treatment of treatment of AD, since SUDD has not a surgical recommendation. The first statements are dedicated to the current indication on antibiotic of in the setting of AD. The first claims that the management of acute diverticulitis without antibiotics does not increase these worse outcomes [63-68]. Therefore, the second statement confirms that antibiotics have to be used by a "case-by-case" basis $[5,66]$, and that some parameters (namely levels of PCR and CT findings at entry) may be predictive on the need to use antibiotics in this population $(48,66)$. The last three statement confirms that the open or the laparoscopic approach to $\mathrm{AD}$, as well as an elective resection after multiple episode of $\mathrm{AD}$ have to follow a "caseby-case" basis $[69,73]$. It is noteworthy the impressive overall consensus about these statements, since disagreement on them among respondents was almost absent.

\section{Critical issues}

6.1 Ambulatory treatment of uncomplicated acute diverticulitis is safe, effective and applicable to patients who do not present concomitant unstable comorbid conditions; immunosuppression; cognitive, social, or psychiatric impairment; and intolerance to oral intake.

Outpatient management allows important cost saving to the health systems without negative influence on the quality 
of life of patients with uncomplicated diverticulitis. [EL: 1a; GR: A]

Consensus levels of agreement: A+60.48\%; A 36.29\%; A$3.23 \%$; D- $0 \%$; D: $0 \%$; D+ 0\%.

6.2 Segmental Colitis Associated with Diverticulosis (SCAD) is a chronic inflammation occurring in the colon harboring diverticulosis that seems to resemble a chronic inflammatory disease rather than a complicated diverticular disease.

Treatment options include antibiotics (Ciproxin and metronidazole), 5-ASA and probiotics for mild cases. In severe disease the use of systemic steroids might be warranted. Anti $T N F \alpha$ treatment may be beneficial in severe disease resistant to other therapeutic options. Treatment duration might vary depending on clinical response and can last weeks-months. [EL: $2 b ; G R: C]$.

Consensus levels of agreement: A+48.39\%; A 41.13\%; A8.87\%; D- 0\%; D: 0\%; D+ 0\%.

6.3 Diverticular inflammation is not a causative risk factor for colorectal cancer (CRC) but is an important factor that should be taken into account requiring early colonoscopy to exclude cancer. [EL: 2a; GR: B].

Consensus levels of agreement: A+73.39\%; A 22.58\%; A4.03\%; D- 0\%; D: 0\%; D+ 0\%.

\section{Comments}

These statements focused their attention on three topics under active debate. The first statement claims about the safety of ambulatory treatment of uncomplicated $\mathrm{AD}$, which is safe and effective [73-79]. Moreover, this approach has also a significant impact on cost-saving [79]. The second statement claims that segmental colitis associated with diverticulosis (SCAD), is a chronic disease occurring in a colon harbouring diverticulosis, and that seems to be a chronic inflammatory bowel disease than a complication of DD [80-83]. This disease may be treated with a variety of treatments, from antibiotic and 5-ASA to anti-TNF $\alpha$ antibodies $[84,85]$. The last statement confirms that DD is not a causative risk factor for colorectal cancer (CRC) [86, 87]. However, it should be excluded in patients after an episode of complicated acute diverticulitis, especially when the colon has not been studied never before [88]. It is noteworthy the impressive overall consensus about these statements, since any disagreement was recorded among respondents.

\section{CONCLUSIONS}

These guidelines represent a consensus of best practice based on the available evidence as showed at the time of the 3rd International Symposium on Diverticular Disease. The statement proposed and voted during this Symposium have been developed starting from the statements voted during the 2nd International Symposium on Diverticular Disease, held in Rome on April 2016 [5], and have been conceived as an improvement of the points in which there were no clear evidence at that time. This is because these guidelines are not described in a classical way ("epidemiology", "diagnosis", "treatment", etc,), as well as no every finding of the disease has been voted or discussed. On the contrary, the sessions (and the statements, as consequence) have been designed just as improvement of that it is already clearly known. The strength of these guidelines is that the statements have been designed by several International experts using a Delphi-like process, and have been approved by a large population of physicians, involving all medical categories managing $\mathrm{DD}$, and coming from European, Northern and Southern America, Australian and African countries.

They may not apply to all situations and should be interpreted in the light of specific clinical situations and resource availability. Further controlled clinical studies may be needed to clarify some aspects of these statements, and revision will definitely be needed, as new data will become available. This is particularly true not only for some medical treatments currently under active debate (in example, how to prevent acute diverticulitis recurrence), but also for some surgical aspects (example when to operate DD).

These Guidelines are not rules, but are intended to be an educational tool to provide information that may assist each medical category (general practitioners, gastroenterologists and surgeons) in providing care to patients, not as encouraging, advocating, requiring, or discouraging any particular treatment.

\section{REFERENCES}

1. Strate LL, Modi R, Cohen E, Spiegel BM. Diverticular disease as a chronic illness: evolving epidemiologic and clinical insights. Am J Gastroenterol 2012;107:1486-1493. doi:10.1038/ajg.2012.194

2. Papa A, Papa V. The Economic Burden of Diverticular Disease. J Clin Gastroenterol 2016;50 Suppl 1:S2-S3. doi:10.1097/ MCG.0000000000000598

3. Kruis W, Germer CT, Leifeld L; German Society for Gastroenterology, Digestive and Metabolic Diseases and The German Society for General and Visceral Surgery. Diverticular disease: guidelines of the german society for gastroenterology, digestive and metabolic diseases and the german society for general and visceral surgery. Digestion 2014;90:190207. doi: $10.1159 / 000367625$

4. Stollman N, Smalley W, Hirano I; AGA Institute Clinical Guidelines Committee. American Gastroenterological Association Institute Guideline on the Management of Acute Diverticulitis. Gastroenterology 2015;149:1944-1949. doi:10.1053/j.gastro.2015.10.003

5. Tursi A, Picchio M, Elisei W, Di Mario F, Scarpignato C, Brandimarte G. Management of Patients With Diverticulosis and Diverticular Disease:Consensus Statements From the 2nd International Symposium on Diverticular Disease. J Clin Gastroenterol 2016;50 Suppl 1:S101-S107. doi:10.1097/MCG.0000000000000654

6. Oxford Centre for Evidence-Based Medicine. Available at: http://www. cebm.net/index.aspx?o=5653

7. Reichert MC, Lammert F. The genetic epidemiology of diverticulosis and diverticular disease: Emerging evidence. United Eur Gastroenterol J 2015;3:409-418. doi:10.1177/2050640615576676

8. Granlund J, Svensson T, Olén O, et al. The genetic influence on diverticular disease--a twin study. Aliment Pharmacol Ther 2012;35:1103-1107. doi:10.1111/j.1365-2036.2012.05069.x

9. Strate LL, Erichsen R, Baron JA, et al. Heritability and Familial Aggregation of Diverticular Disease: A Population-Based Study of Twins 
and Siblings. Gastroenterology 2013;144:736-742.e1. doi: 10.1053/j. gastro.2012.12.030

10. Connelly TM, Berg AS, Hegarty JP, et al. The TNFSF15 Gene Single Nucleotide Polymorphism rs7848647 Is Associated With Surgical Diverticulitis. Ann Surg 2014;259:1132-1137. doi:10.1097/ SLA.0000000000000232

11. Reichert MC, Kupcinskas J, Krawczyk M, et al. A Variant of COL3A1 (rs3134646) Is associated with risk of developing diverticulosis in white men. Dis Colon Rectum 2018;61:604-611. doi:10.1097/ DCR.0000000000001001

12. Sigurdsson S, Alexandersson KF, Sulem P, et al. Sequence variants in ARHGAP15, COLQ and FAM155A associate with diverticular disease and diverticulitis. Nat Commun 2017; 8:15789. doi:10.1038/ ncomms15789

13. Maguire $\mathrm{lH}$, Handelman SK, Du X, Chen Y, Pers TH, Speliotes EK. Genome-wide association analyses identify 39 new susceptibility loci for diverticular disease. Nat Genet 2018; 50:1359-1365. doi:10.1038/ s41588-018-0203-z

14. Schafmayer C, Harrison JW, Buch S, et al. Genome-wide association analysis of diverticular disease points towards neuromuscular, connective tissue and epithelial pathomechanisms. Gut 2019;68:854865. doi:10.1136/gutjnl-2018-317619

15. Bassotti G, Battaglia E, Bellone G, et al. Interstitial cells of Cajal, enteric nerves, and glial cells in colonic diverticular disease. J Clin Patho 2005;58:973-977. doi:10.1136/jcp.2005.026112

16. Fornai M, Colucci R, Antonioli L, et al. Role of cyclooxygenase isoforms in the altered excitatory motor pathways of human colon with diverticular disease. Br J Pharmacol 2014;171:3728-3740. doi:10.1111/ bph. 12733

17. Bassotti G, Villanacci V, Bernardini N, Dore MP. Diverticular Disease of the Colon: neuromuscular Function Abnormalities. J Clin Gastroenterol 2016;50 (Suppl 1):S6-S8. doi:10.1097/MCG.0000000000000578

18. Bassotti G, Battaglia E, De Roberto G, Morelli A, Tonini M, Villanacci V. Alterations in colonic motility and relationship to pain in colonic diverticulosis. Clin Gastroenterol Hepatol 2005;3:248-253. doi:10.1016/ s1542-3565(04)00614-7

19. Bassotti G, Villanacci V, Nascimbeni R, et al. The role of colonic mast cells and myenteric plexitis in patients with diverticular disease. Int J Colorectal Dis 2013;28:267-272. doi:10.1007/s00384-012-1554-Z

20. Humes DJ, Simpson J, Smith J, et al. Visceral hypersensitivity in symptomatic diverticular disease and the role of neuropeptides and low grade inflammation. Neurogastroenterol Motil 2012;24:318-e163. doi:10.1111/j.1365-2982.2011.01863.x

21. Tursi A. Endoscopic Diagnosis of Diverticulosis and Diagnosis of Symptomatic Uncomplicated Diverticular Disease of the Colon: If You Properly Classify, You Properly Make the Diagnosis. Am J Gastroenterol 2019;114: 1349-1350. doi: 10.14309/ajg.0000000000000293

22. Peery AF, Keku TO, Addamo C, et al. Colonic Diverticula Are Not Associated With Mucosal Inflammation or Chronic Gastrointestinal Symptoms. Clin Gastroenterol Hepatol 2018;16:884891.e1. doi:10.1016/j.cgh.2017.05.051

23. Järbrink-Sehgal ME, Rassam L, Jasim A, et al. Diverticulosis, Symptoms and Colonic Inflammation:A Population-Based Colonoscopy Study. Am J Gastroenterol 2019;114:500-510. doi:10.14309/ajg.0000000000000113

24. Humes DJ, Simpson J, Smith J, et al. Visceral hypersensitivity in symptomatic diverticular disease and the role of neuropeptides and low grade inflammation. Neurogastroenterol Motil 2012;24:318-e163. doi:10.1111/j.1365-2982.2011.01863.x
25. Tursi A, Brandimarte G, Elisei W, et al. Assessment and grading of mucosal inflammation in colonic diverticular disease. J Clin Gastroenterol 2008;42:699-703. doi:10.1097/MCG.0b013e3180653ca2

26. Aldoori WH, Giovannucci EL, Rimm EB, Wing AL, Trichopoulos DV, Willett WC. A prospective study of diet and the risk of symptomatic diverticular disease in men. Am J Clin Nutr 1994;60:757-764. doi:10.1093/ajcn/60.5.757

27. Aldoori WH, Giovannucci EL, Rockett HR, Sampson L, Rimm EB, Willett WC. A prospective study of dietary fiber types and symptomatic diverticular disease in men. J Nutr 1998;128:714-719. doi:10.1093/ jn/128.4.714

28. Crowe FL, Appleby PN, Allen NE, Key TJ. Diet and risk of diverticular disease in Oxford cohort of European Prospective Investigation into Cancer and Nutrition (EPIC):prospective study of British vegetarians and non-vegetarians. BMJ 2011;343:d4131. doi:10.1136/bmj.d4131

29. Crowe FL, Balkwill A, Cairns BJ, et al. Source of dietary fibre and diverticular disease incidence:a prospective study of UK women. Gut 2014;63:1450-1456. doi:10.1136/gutjnl-2013-304644

30. Strate LL, Keeley BR, Cao Y, Wu K, Giovannucci EL, Chan AT. Western Dietary Pattern Increases, and Prudent Dietary Pattern Decreases, Risk of Incident Diverticulitis in a Prospective Cohort Study. Gastroenterology 2017;152:1023-1030.e2. doi:10.1053/j. gastro.2016.12.038

31. Hjern F, Wolk A, Hakansson N. Obesity, physical inactivity, and colonic diverticular disease requiring hospitalization in women:a prospective cohort study. Am J Gastroenterol 2012;107:296-302. doi:10.1038/ ajg.2011.352

32. Ma W, Jovani M, Liu PH, et al. Association Between Obesity and Weight Change and Risk of Diverticulitis in Women. Gastroenterology 2018;155:58-66.e4. doi:10.1053/j.gastro.2018.03.057

33. Cuomo R. Barbara G, Andreozzi P, et al. Symptom patterns can distinguish diverticular disease from irritable bowel syndrome. Eur J Clin Invest 2013;43:1147-1155. doi:10.1111/eci.12152

34. Tursi A, Elisei W, Picchio M, Giorgetti GM, Brandimarte G. Moderate to severe and prolonged left lower-abdominal pain is the best symptom characterizing symptomatic uncomplicated diverticular disease of the colon: a comparison with fecal calprotectin in clinical setting. J Clin Gastroenterol 2015;49:218-221. doi:10.1097/MCG.0000000000000094

35. Tursi A, Brandimarte G, Elisei W, Giorgetti GM, Inchingolo CD, Aiello F. Faecal calprotectin in colonic diverticular disease:a case-control study. Int J Colorectal Dis 2009;24:49-55. doi:10.1007/s00384-008-0595-9

36. Tursi A, Elisei W, Brandimarte G, et al. Mucosal expression of basic fibroblastic growth factor, Syndecan 1 and tumor necrosis factoralpha in diverticular disease of the colon:a case-control study. Neurogastroenterol Motil 2012;24:836-e396. doi:10.1111/j.13652982.2012.01946.x

37. Tursi A. Mastromarino P, Capobianco D, et al. Assessment of fecal microbiota and fecal metabolome in symptomatic uncomplicated diverticular disease of the colon. J Clin Gastroenterol 2016;50 Suppl 1:S9-S12. doi:10.1097/MCG.0000000000000626

38. Barbara G, Scaioli E, Barbaro MR, et al. Gut microbiota, metabolome and immune signatures in patients with uncomplicated diverticular disease. Gut 2017;66:1252-1261. doi:10.1136/gutjnl-2016-312377

39. Kvasnovsky CL, Leong LEX, Choo JM, et al. Clinical and symptom scores are significantly correlated with fecal microbiota features in patients with symptomatic uncomplicated diverticular disease:a pilot study. Eur J Gastroenterol Hepatol 2018;30:107-112. doi:10.1097/ MEG.0000000000000995 
40. Gao R, Tao Y, Zhou C, et al. Exercise therapy in patients with constipation:a systematic review and meta-analysis of randomized controlled trials. Scand J Gastroenterol 2019;54:169-177. doi:10.1080/ 00365521.2019.1568544

41. Lahat A, Necula D, Yavzori M, et al. Prolonged Recurrent Abdominal Pain is Associated With Ongoing Underlying Mucosal Inflammation in Patients who had an Episode of Acute Complicated Diverticulitis. J Clin Gastroenterol 2019;53:e178-e185. doi:10.1097/MCG.0000000000000980

42. Tursi A, Elisei W, Giorgetti GM, et al. Detection of endoscopic and histological inflammation after an attack of colonic diverticulitis is associated with higher diverticulitis recurrence. J Gastrointestin Liver Dis 2013;22:13-19.

43. Bianchi M, Festa V, Moretti A, et al. Meta-analysis: long-term therapy with rifaximin in the management of uncomplicated diverticular disease. Aliment Pharmacol Ther 2011;33:902-910. doi:10.1111/j.13652036.2011.04606.x

44. Raskin JB, Kamm MA, Jamal MM, et al. Mesalamine did not prevent recurrent diverticulitis in phase 3 controlled trials. Gastroenterology 2014;147:793-802. doi:10.1053/j.gastro.2014.07.004

45. Stollman N, Magowan S, Shanahan F, Quigley EM; DIVA Investigator Group. A randomized controlled study of mesalamine after acute diverticulitis:results of the DIVA trial. J Clin Gastroenterol 2013;47:621629. doi:10.1097/MCG.0b013e31828003f6

46. Picchio M, Elisei W, Tursi A. Mesalazine to treat symptomatic uncomplicated diverticular disease and to prevent acute diverticulitis occurrence. A systematic review with meta-analysis of randomized, placebo-controlled trials. J Gastrointestin Liver Dis 2018;27:291-297. doi:10.15403/jgld.2014.1121.273.pic

47. Andeweg CS, Knobben L, Hendriks JC, Bleichrodt RP, van Goor H How to diagnose acute left-sided colonic diverticulitis. Proposal for a clinical scoring system. Ann Surg 2011;253:940-946.doi:10.1097/ SLA.0b013e3182113614

48. Mäkelä JM, Klintrup K, Takala H, Rautio T. The role of C-reactive protein in prediction of the severity of acute diverticulitis in an emergency unit. Scand J Gastroenterol 2015;50:536-541. doi:10.3109/ 00365521.2014 .999350

49. Ambrosetti P. Acute left-sided colonic diverticulitis:clinical expressions, therapeutic insights, and role of computed tomography. Clin Exp Gastroenterol 2016;9:249-257. doi:10.2147/CEG.S110428

50. Lameris W, Van Randen A, Bipat S, Bossuyt PM, Boermeester MA, Stoker J. Graded compression ultrasonography and computed tomography in acute colonic diverticulitis:meta-analysis of test accuracy. Eur Radiol 2008;18:2498-2511. doi:10.1007/s00330-008-1018-6

51. Dirks K, Calabrese E, Dietrich CF, et al. EFSUMB Position Paper: Recommendations for Gastrointestinal Ultrasound (GIUS) in Acute Appendicitis and Diverticulitis. Ultraschall Med 2019;40:163-175. doi:10.1055/a-0824-6952

52. Van Randen A, Lameris W, van Es HW, et al. A comparison of the accuracy of ultrasound and computed tomography in common diagnoses causing acute abdominal pain. Eur Radiol 2011;21:15351545. doi:10.1007/s00330-011-2087-5

53. Longstreth GF. Epidemiology and outcome of patients hospitalized with acute lower gastrointestinal hemorrhage: a population-based study. Am J Gastroenterol 1997;92:419-424.

54. Nagata N, Niikura R, Aoki T, et al. Colonic diverticular hemorrhage associated with the use of nonsteroidal anti-inflammatory drugs, low-dose aspirin, antiplatelet drugs, and dual therapy. J Gastroenterol Hepatol 2014;19:1786-1793. doi:10.1111/jgh.12595
55. Wong Kee Song LM, Baron TH. Endoscopic management of acute lower gastrointestinal bleeding. Am J Gastroenterol 2008;103:1881-1887.

56. Tursi A, Brandimarte G, Di Mario F, et al. Development and validation of an endoscopic classification of diverticular disease of the colon: the DICA classification. Dig Dis 2015;33:68-76. doi:10.1159/000366039

57. Tursi A, Brandimarte G, Di Mario F, et al; DICA Collaborative Group. Predictive value of the Diverticular Inflammation and Complication Assessment (DICA) endoscopic classification on the outcome of diverticular disease of the colon: An international study. United European Gastroenterol J 2016;4:604-613. doi:10.1177/2050640615617636

58. Tursi A, Brandimarte G, Di Mario F, et al; DICA Italian Group. The "DICA" endoscopic classification for diverticular disease of the colon shows a significant interobserver agreement among community endoscopists. J Gastrointestin Liver Dis 2019;28:23-27. doi:10.15403/ jgld.2014.1121.281.dic

59. Papi C, Ciaco A, Koch M, Capurso L. Efficacy of rifaximin in the treatment of symptomatic diverticular disease of the colon. A multicenter double-blind placebo-controlled trial. Aliment Pharmacol Ther 1995;9:33-39. doi:10.1111/j.1365-2036.1995.tb00348.x

60. Kruis W, Meier E, Schumacher M, et al; German SAG-20 Study Group. Randomised clinical trial: mesalazine (Salofalk granules) for uncomplicated diverticular disease of the colon--a placebo-controlled study. Aliment Pharmacol Ther 2013;37:680-690. doi:10.1111/apt.12248

61. Tursi A, Brandimarte G, Elisei W, et al. Randomised clinical trial mesalazine and/or probiotics in maintaining remission of symptomatic uncomplicated diverticular disease--a double-blind, randomised, placebo-controlled study. Aliment Pharmacol Ther 2013;38:741-751. doi:10.1111/apt.12463

62. Kvasnovsky CL, Bjarnason I, Donaldson AN, Sherwood RA, Papagrigoriadis S. A randomized double-blind placebo-controlled trial of a multi-strain probiotic in treatment of symptomatic uncomplicated diverticular disease. Inflammopharmacology 2017 May 20. doi:10.1007/s10787-017-0363-y

63. Emile SH, Elfeki H, Sakr A, Shalaby M. Management of acute uncomplicated diverticulitis without antibiotics:a systematic review, meta-analysis, and meta-regression of predictors of treatment failure. Tech Coloproctol 2018;22:499-509. doi:10.1007/s10151-018-1817-y

64. Mocanu V, Dang JT, Switzer N, et al. The role of antibiotics in acute uncomplicated diverticulitis:A systematic review and meta-analysis. Am J Surg 2018;216:604-609. doi:10.1016/j.amjsurg.2018.01.039

65. Desai M, Fathallah J, Nutalapati V, Saligram S. Antibiotics Versus No Antibiotics for Acute Uncomplicated Diverticulitis: A Systematic Review and Meta-Analysis. Dis Colon Rectum 2019;62:1005-1012. doi:10.1097/DCR.0000000000001324

66. Azhar N, Kulstad H, Pålsson B, Kurt Schultz J, Lydrup ML, Buchwald P. Acute uncomplicated diverticulitis managed without antibiotics difficult to introduce a new treatment protocol but few complications. Scand J Gastroenterol 2019;54:64-68. doi:10.1080/00365521.2018.155 2987

67. Tandon A, Fretwell VL, Nunes QM, Rooney PS. Antibiotics versus no antibiotics in the treatment of acute uncomplicated diverticulitis - a systematic review and meta-analysis. Colorectal Dis 2018 Jan 11. doi:10.1111/codi.14013

68. Au S, Aly EH. Treatment of Uncomplicated Acute Diverticulitis Without Antibiotics:A Systematic Review and Meta-Analysis. Dis Colon Rectum 2019;62:1533-1547. doi:10.1097/DCR.0000000000001330

69. Di Saverio S. Emergency laparoscopy: a new emerging discipline for treating abdominal emergencies attempting to minimize costs and 
invasiveness and maximize outcomes and patients' comfort. J Trauma Acute Care Surg 2014;77:338-350. doi:10.1097/TA.0000000000000288

70. Klarenbeek BR, Veenhof AA, Bergamaschi R, et al. Laparoscopic sigmoid resection for diverticulitis decreases major morbidity rates: a randomized control trial:short-term results of the Sigma Trial. Ann Surg 2009;249:39-44. doi:10.1097/SLA.0b013e31818e416a

71. Gervaz P, Inan I, Perneger T, Schiffer E, Morel P. A prospective, randomized, single-blind comparison of laparoscopic versus open sigmoid colectomy for diverticulitis. Ann Surg 2010;252:3-8. doi:10.1097/SLA.0b013e3181dbb5a5

72. Cirocchi R, Farinella E, Trastulli S, Sciannameo F, Audisio RA. Elective sigmoid colectomy for diverticular disease. Laparoscopic vs open surgery: a systematic review. Colorectal Dis 2012;14:671-683. doi:10.1111/j.1463-1318.2011.02666.x

73. Kohl A, Rosenberg J, Bock D, et al. Two-year results of the randomized clinical trial DILALA comparing laparoscopic lavage with resection as treatment for perforated diverticulitis. Br J Surg 2018;105:1128-1134. doi:10.1002/bjs.10839

74. Isacson D, Thorisson A, Andreasson K, Nikberg M, Smedh K, Chabok A. Outpatient, non-antibiotic management in acute uncomplicated diverticulitis:a prospective study. Int J Colorectal Dis 2015;30:1229 1234. doi:10.1007/s00384-015-2258-y

75. Biondo S, Golda T, Kreisler E, et al. Outpatient versus hospitalization management for uncomplicated diverticulitis: a prospective, multicenter randomized clinical trial (DIVERTrial). Ann Surg 2014;259:38-44. doi:10.1097/SLA.0b013e3182965a11

76. Sánchez-Velázquez P, Grande L, Pera M. Outpatient treatment of uncomplicated diverticulitis: a systematic review. Eur J Gastroenterol Hepatol 2016;28:622-627. doi:10.1097/MEG.0000000000000610

77. Bolkenstein HE, Draaisma WA, van de Wall B, Consten E, Broeders I. Treatment of acute uncomplicated diverticulitis without antibiotics: risk factors for treatment failure. Int J Colorectal Dis 2018;33:863-869. doi:10.1007/s00384-018-3055-1

78. Rottier SJ, van Dijk ST, Ünlü Ç, van Geloven AAW, Schreurs WH, Boermeester MA. Complicated Disease Course in Initially Computed
Tomography-Proven Uncomplicated Acute Diverticulitis. Surg Infect (Larchmt) 2019;20:453-459. doi:10.1089/sur.2018.289

79. Mills AM, Holena DN, Kallan MJ, Carr BG, Reinke CE, Kelz RR. Effect of insurance status on patients admitted for acute diverticulitis. Colorectal Dis 2013;15:613-620. doi:10.1111/codi.12066

80. Tursi A. Segmental colitis associated with diverticulosis: complication of diverticular disease or autonomous entity? Dig Dis Sci 2011;56:27-34 doi:10.1007/s10620-010-1230-5

81. Imperiali G, Meucci G, Alvisi C, et al. Segmental colitis associated with diverticula:a prospective study. Gruppo di Studio per le Malattie Infiammatorie Intestinali (GSMII). Am J Gastroenterol 2000;95:1014-1016.

82. Mann NS, Hoda KK. Segmental colitis associated with diverticulosis: systematic evaluation of 486 cases with meta-analysis. Hepatogastroenterology 2012;59:2119-2112.

83. Ludeman L, Shepherd NA. What is diverticular colitis? Pathology 2002;34:568-572. doi:10.1080/0031302021000035974

84. Schembri J, Bonello J, Christodoulou DK, Katsanos KH, Ellul P. Segmental colitis associated with diverticulosis: is it the coexistence of colonic diverticulosis and inflammatory bowel disease? Ann Gastroenterol 2017;30:257-261. doi:10.20524/aog.2017.0126

85. Tursi A, Elisei W, Giorgetti GM, et al. Segmental colitis associated with diverticulosis: a 5-year follow-up. Int J Colorectal Dis 2012;27:179-185. doi:10.1007/s00384-011-1296-3

86. Huang WY, Lin CC, Jen YM, et al. Association between colonic diverticular disease and colorectal cancer: a nationwide populationbased study. Clin Gastroenterol Hepatol 2014;12:1288-1294 doi:10.1016/j.cgh.2013.11.039

87. Mortensen LQ, Burcharth J, Andresen K, Pommergaard HC, Rosenberg J. An 18-Year nationwide cohort study on the association between diverticulitis and colon cancer. Ann Surg 2017;265:954-959. doi:10.1097/SLA.0000000000001794

88. Meyer J, Orci LA, Combescure C, et al. Risk of Colorectal Cancer in Patients With Acute Diverticulitis: A Systematic Review and Metaanalysis of Observational Studies. Clin Gastroenterol Hepatol 2019;17:1448-1456.e17. doi:10.1016/j.cgh.2018.07.031 